PAPER

\title{
Good medical ethics, from the inside out—and back again
}

\author{
Justin Oakley
}

\section{Correspondence to}

Associate Professor Justin Oakley, Centre for Human Bioethics, Monash University, Clayton, VIC 3800, Australia; justin.oakley@monash.edu

Received 31 August 2014 Accepted 2 October 2014
ABSTRACT

I argue here that good medical ethics requires an empirically-informed moral psychology of medical virtue along with sound action-guiding prescriptions for virtuous medical practice. After distinguishing between three levels of justification, I indicate how medical virtue ethics can draw constructively on relevant empirical research in developing feasible and realistic aspirational standards for doctors, and in evaluating how policymakers can support doctors in acting on the virtues that doctors agreed to be guided by when they joined the profession.

...one ought to choose that which is intermediate, not the excess nor the defect..., but if a man had only this knowledge he would be none the wisereg, we should not know what sort of medicines to apply to our body if some were to say 'all those which the medical art prescribes, and which agree with the practice of one who possesses the art ${ }^{1}$

As Aristotle ${ }^{1}$ recognised long ago, both living well and good medical practice require not only a highly-developed contextual awareness, but also an understanding of the relevant standards of correctness or excellence which can be internalised as normative dispositions to guide our actions. But while gathering observations of human life and medical practice is ideally directed towards developing generalisations, standards and rules to guide us, working adequately with those standards and rules can hardly be just an analytic exercise. For whatever the merits of a purely analytic medical ethics, doing medical ethics well involves appreciating the need for a dynamic relationship between theory and practice-better characterised, perhaps, as synthetic medical ethics. Indeed, the idea of doing good medical ethics from the inside out and back again suggests a role for relevant empirical research in at least two places, at both ends of the dialectic - that is, in developing a sound moral psychology of ethical medical practice, and in determining the likely impact of certain ethical prescriptions on medical practice. Also, formulating ethically justifiable policies to regulate medical practice may require us to reach back into empirical research in social and moral psychology, at least in aiming to achieve certain sorts of policy goals, such as protecting the therapeutic orientation of doctorpatient relationships.

\section{TAKING SERIOUSLY THE INTERNAL MORALITY OF MEDICINE AGAINST THE BACKGROUND OF BROAD-BASED MORALITY}

A notable aspect of the emergence of more systematic and theoretically sophisticated medical ethics and bioethics in the 1970s was the ground-breaking application of broad-based ethical theories like utilitarianism and Kantian ethics directly to issues in medical practice, such as paternalism and end-of-life decision-making. These critiques were somewhat liberating for patients, in reminding doctors of the importance of recognising patients' own values, and of the harms that can result from doctors adopting a survival-at-all-costs mentality in patient care. However, these direct applications of ethical theories to issues in medical practice were subsequently found to be insufficient, as they tended to neglect ethically distinctive roledifferentiated features of medical practice-as Larry Churchill reminds us, 'the moral sensibilities of doctors [need to] be tuned to different nuances of situations than those of individuals who do not practice medicine'. ${ }^{2}$ It was thus acknowledged that acting ethically in medicine requires not only familiarity with broader moral standards but also an understanding of what it is right, qua doctor, for one to do in the circumstances, considering the distinctive values and goals of medicine-such as doctors' commitments to act in their patients' best interests. So, for instance, it is primarily due to this specific commitment, more than any broader ethical standards, that doctors can justifiably refuse on grounds of professional integrity patients' requests for futile interventions, by saying 'I cannot with my doctor's hat on do that for you'.

Indeed, doctors' role-differentiated moral commitments are not simply applications or specifications of broad-based moral standards, as they can also reveal strengths and limitations of those standards. For instance, the emphasis in general practice on the importance of developing enduring doctor-patient relationships might not be readily reconcilable with utilitarian ethical demands, which may require doctors to distribute their medical services more widely. ${ }^{3}$ The interaction between medical ethics and general ethics must be seen as a two-way street-and for this to function well, it must include seeing how the findings of any such analysis square with empirical studies of medical practice and doctor-patient relationships. Justifications which might sound plausible from the armchair can turn out to be far less plausible when 
considered in the context of clinical practice, and this checking and substantiating are important for proponents of arguments with empirical premises to supply the evidential warrant to avoid scare-mongering and wishful thinking-and the larger the claim, the greater the substantiation which is required. ${ }^{4}$

Of course, to recognise in doing good medical ethics 'the internal morality of medicine' does not entail uncritically accepting current mores in medical practice. Serving patient health is undoubtedly a central goal of medicine, but there are clearly better and worse ways of meeting this goal. For instance, providing a patient with adequate information about their diagnosis and prognosis is generally in their best health interests, whatever doctors' entrenched practices on such matters might be in particular cultures or historical periods. And there has clearly been much moral progress in medical practice in recent decades-current medical mores generally serve the proper goals of medicine better than did medical mores in earlier eras. For example, where the inaugural 1847 American Medical Association Code of Ethics seemed to endorse paternalistic practices in exhorting doctors to 'unite....condescension with authority' in their patient consultations, ${ }^{5}$ no current code of medical ethics would advise such conduct. This transition can be seen as moral progress, rather than as simply reflecting changes in professional practice over the ensuing period, because respecting patient autonomy evidently better serves the proper goals of medicine (insofar as it promotes patient health), while recognising a crucial side-constraint on serving proper medical goals, than does paternalistic behaviour by doctors.

Nevertheless, doctors still need to understand the broader moral limits on their roles as doctors, and how those limits restrict what they can justifiably do for their patients, all things considered. (No profession plausibly has complete moral autonomy.) And this is the case, whatever broader ethical perspective one takes in setting such boundaries around medical ethics. Shifting to one level of abstraction, doing good medical ethics also involves doing good professional ethics. Thus, doctors, like all professionals, are justifiably expected to make their services broadly available, rather than picking and choosing their patients according to personal preference. Indeed, doctors' obligations to respect patient autonomy, and to act justly with the resources at their disposal, can themselves be understood as examples of generic obligations which apply to all professionals, in the relevant contexts. Lawyers, for instance, also have professional obligations to respect their clients' autonomy, and to consider fairness in deciding how to ethically allocate their special expertise among potential clients. At a further level of abstraction, doctors' specific medical obligations and virtues, and their generic professional obligations and virtues, are also limited by broad-based ethical obligations and values. The question of whether doctors ought to breach patient confidentiality to protect third parties from serious harm provides a good illustration of these layers of value. The internal morality of medicine alone may well be inadequate for determining whether psychiatrists ought to take steps to see that third parties are warned of credible threats of significant harm by patients. However, taking a larger perspective by considering psychiatrists' broader ethical obligations to the community as professionals, or more generally, their ethical obligations as persons (such as a general duty of beneficence), brings into view justifications for why they ought to take steps to warn third parties in such cases, and thus provides a more intuitively plausible answer here.

So, doing good medical ethics also involves doing good professional ethics and good broad-based ethics, and understanding the interrelations between these. Good medical ethics is thereby sensitive to context, but without abandoning ethical principles and more theoretical considerations in doing so.

\section{THE ROLE OF EMPIRICAL RESEARCH IN MEDICAL VIRTUE ETHICS}

An attractive feature of virtue ethics approaches to medical ethics is the importance such approaches give to this back-and-forth movement between broad-based moral standards and the distinctive values of medical ethics. These approaches also illustrate well how doing good empirically-informed medical ethics involves appreciating the relevance of empirical research at both ends of these layers of value-that is, not only in developing action-guidance which takes account of the realities of clinical practice and behaviour, but also in developing a realistic moral psychology to underpin these prescriptions for action. ${ }^{i}$ For example, in their virtue ethics approach to psychiatry, Jennifer Radden and John Sadler outline the proper goals of psychiatric practice, and then go on to develop an evidencebased account of role virtues-such as 'unselfing' and 'realism'-which have been shown to help therapists serve the proper goals of their role. ${ }^{6}$ This account recognises the realities of mental healthcare, where patients are commonly asked to reveal highly intimate details about themselves and so are particularly vulnerable in this context to therapists who lack the relevant professional virtues, and these features make the professional character traits manifested by psychiatrists towards their patients especially crucial to the success of therapy. Similarly, Rosalind McDougall's virtue ethics analysis of prebirth testing evaluates the ethics of various embryo selection decisions in terms of an empirically-informed account of parental virtuessuch as 'acceptingness' - which demonstrably help parents to promote their child's flourishing, clearly a central goal of parenting. ${ }^{7}$

Empirical research needs to inform normative claims in applied virtue ethics not only at the theory-building stage, by clarifying the proper goals of professional and other roles, and in substantiating or undermining various candidate role virtues for individuals acting in such contexts, but also in checking the directives provided by such an approach against the realities of practice in the relevant role. For example, doctors being encouraged by medical clinics to tell patients about any financial or other ties with the pharmaceutical and medical device industries can be justified as an exercise of the generic professional virtue of honesty, and as thereby meeting the ethical demand to respect patient autonomy (as a side-constraint on the requirement to serve the best interests of one's patients). But while that would clearly be a step forward in addressing medical conflicts of interest in this context, it can be demonstrated to fall short of a complete solution where the evidence indicates that the prescribing decisions of many doctors who are then more transparent about their industry ties are still unduly influenced by those ties in ways which fail to serve their patients' best interests. ${ }^{8}$ ii And, indeed, the evidence of such undue influence in this context does suggest that the generic professional virtue of honesty needs to be supplemented by the specific virtue of medical beneficence in doctors' drug prescribing behaviour. ${ }^{9} 10$

${ }^{\mathrm{i}}$ I am here referring to stand-alone virtue ethics approaches to medical ethics, rather than to virtue theories provided as necessary supplements to what are fundamentally deontological or utilitarian approaches.

ii It will be important to monitor whether the new US Open Payments program, introduced in September 2014, is any more successful at curbing this undue influence (see: http:/www.cms.gov/openpayments/ index.html). 
Genuinely having a particular virtue requires getting things right, or a level of success, in the actions promoted by, for example, a medically beneficent disposition. 'Acting virtuously' is a 'success term', and in this respect is analogous to terms like 'refute', rather than terms like 'deny'. ${ }^{11}$ iii We can all readily appreciate that the 'well-intentioned, bungling do-gooder', ${ }^{13}$ in Robert Veatch's memorable phrase, could hardly serve as an exemplar of a virtuous doctor. And to 'get things right', to act in ways which can reasonably be expected to help patients' health interests, one must also take seriously empirical research on what does and what does not work in clinical practice. Further, since acting beneficently qua doctor requires acting from certain motives and dispositions (or regulative ideals), such as a particularistic care for the patient and a commitment to their genuine welfare (rather than from unreflective assumptions about what might be best for them), empirical research into the nature of such motives and dispositions, and their effectiveness in medical practice (compared, say, with various situational factors), is also crucial for developing an adequate moral psychology of medical virtue.

Further, good medical ethics should not only consider the morality of doctors' individual decisions and actions, but would also examine the ethical justifiability or otherwise of the policies and regulations under which the medical profession as a whole practice-and empirical research is clearly indispensable there, also. For example, from the perspective of medical ethics, addressing the question of whether to legalise direct-to-consumer advertising (DTCA) of prescription pharmaceuticals requires investigating available evidence of how legalised pharmaceutical DTCA affects the role of the doctor, and what impact such advertising evidently has on patient health outcomes and doctorpatient relationships. From a virtue ethics perspective, evaluating a proposal to legalise pharmaceutical DTCA would include considering evidence on whether such advertising promotes or is detrimental to patient health overall-but this evaluation would arguably also place considerable weight on studies of whether or not allowing such advertising undermines doctors having and acting on virtues such as medical beneficence, which they committed to being guided by when they joined the profession. For while a virtue ethics evaluation of the morality of individual doctors' actions requires adverting to (among other things) the motives from which a doctor acted in a given case (and empirical research can help us understand what sorts of motives doctors actually act on and what sorts of factors influence their motives), evaluating a policy that regulates the conduct of the profession as a whole arguably requires a shift in focus from the doctor's motives to the normative dispositions or governing conditions which the medical profession applies to doctor-patient relationships in various contexts. This shift in the grounds of evaluation when evaluating policies rather than individual actions is analogous to utilitarianism's change in focus when used to evaluate individual acts, or when used to evaluate public policies and laws. As Hare argues, a utilitarian approach to public policy would consider whether legalising a certain practice-such as commercial surrogacy or markets in organs-would maximise

\footnotetext{
iii Gilbert Ryle refers to verbs such as 'win', 'find', and 'prove' as 'success words' or 'achievement words', and he comments that 'in applying an achievement verb we are asserting that some state of affairs obtains over and above that which consists in the performance, if any, of the subservient task activity' (143-4). ${ }^{11}$ Compare, for example, 'kicking' with 'scoring'. See also Christine Swanton's discussion of the importance of 'hitting the target' of the contextually-relevant virtue, in reference 12 .
}

utility overall, even if certain individuals engaging in commercial surrogacy or organ selling would not maximise utility, considered in themselves. ${ }^{\text {iv }}$ With both virtue ethics and utilitarianism, the basis of the evaluation alters, depending on the scope of what is being evaluated.

An ethically appropriate governing condition of a doctor's prescribing behaviour, for example, is a commitment to acting in their patients' best interests, whether or not a doctor also has feelings of concern for the patient among their motives in prescribing the requisite medication for the patient. Doctors are expected to maintain therapeutic relationships with their patients. ${ }^{v}$ And, for a doctor-patient relationship to qualify as a therapeutic relationship, it must not only promote the patient's health, but it must also be one where the doctor is guided or governed in their clinical decision-making by a commitment to serving their patient's best health interests. For example, a doctor whose prescribing decisions in environments of legalised pharmaceutical DTCA are governed by a commitment to meeting their patient's medication requests, despite any strong misgivings about the clinical appropriateness of those requests, arguably does not have a therapeutic relationship with that patient (whatever the long-term outcomes for the patient of their receiving all of the requested medications). ${ }^{\text {vi }}$ So, empirical studies of the extent to which doctors in such environments are acquiescing to such requests in those circumstances are clearly crucial to understanding the impact of legalised pharmaceutical DTCA on doctor-patient relationships. ${ }^{16}$ And, because the nature of doctor-patient relationships is defined (as therapeutic or otherwise) in part by their governing conditions, which are also some of the key normative dispositions involved in virtues, it follows that doctors' medical virtues (or lack thereof) are shown in the nature of the doctor-patient relationships that they develop and maintain with their patients. ${ }^{\text {vii }}$ Therefore, when states support (or fail to support) doctors developing and maintaining therapeutic relationships with their patients, states are thereby supporting (or failing to support) doctors having and acting on the medical virtues which they committed to having when they joined the profession. Here again, empirical research in moral and social psychology is indispensable. For virtue ethics could support not only stricter regulation (or even prohibition) of such advertising (so that patients have a better grasp of the risks and benefits of the advertised drugs they might be requesting), but it could also support steps being taken by the state to strengthen doctors' medical virtues so that they are less inclined to acquiesce to such requests-and empirical research may reveal that both situational and character or dispositional factors have a role to play in such efforts.

\footnotetext{
${ }^{\text {iv }}$ Reasoning about moral questions should start by asking what we would be doing if we followed a certain proposal. And what we would be doing is bringing about certain consequences. So what we have to ask first is: what consequences would we be bringing about if we followed it? That is what any responsible government, and any responsible committee advising a government has to ask first' (See reference 14).

'See, for example, the Australian Medical Association's (AMA) current Code of Ethics, which advises that doctors must 'Recognise that an established therapeutic relationship between doctor and patient must be respected' (1.1.14) (https://ama.com.au/codeofethics).

${ }^{\mathrm{vi}}$ For an elaboration of this argument, see reference 15.

viiperhaps not just any change from a relationship being therapeutic will indicate the presence or absence of medical virtue in the doctor in question. For instance, it might be implausible to describe a relationship as therapeutic where a doctor has been prescribing a course of medication which unforeseeably turns out to significantly harm the patient, though such an outcome may have little, if anything, to do with the presence or absence of medical virtue in the doctor.
} 


\section{CONCLUSIONS}

Good medical ethics in the virtue ethics tradition makes extensive use of empirical research, both in developing a well-grounded moral psychology of medical virtue, and in checking how proposed action-guidance might help or hinder doctors in serving the proper goals of medicine. This reciprocal relationship between theory and practice echoes Aristotle's own methodology in ethics, ${ }^{17}$ where he regularly compares his provisional conclusions about eudaimonia with his observations about the flourishing or otherwise of individuals in human communities. Virtue ethics is well known for proceeding 'from the inside out', but it is also important to appreciate that taking ethical prescriptions outside into the complex and difficult world of medical practice can often tell us as much about the pros and cons of those prescriptions as it can about how medical practice should be reformed.

Competing interests None.

Provenance and peer review Commissioned; internally peer reviewed.

\section{REFERENCES}

1 Aristotle. Nicomachean ethics. VI, 1, 1138b29-33.

2 Churchill LR. Reviving a distinctive medical ethic. Hastings Cent Rep 1989;3:33.

3 Oakley J, Cocking D. Virtue ethics and professional roles. Cambridge: Cambridge University Press, 2001:102-11
4 Oakley J, Cocking D. Consequentialism, complacency, and slippery slope arguments. Theor Med Bioeth 2005;3:227-39.

5 Code of Ethics of the American Medical Association. Philadelphia: Collins Printers, 1847, Article 1, Chapter 1, p. 7. https://ia601202.us.archive.org/15/items/ 63310410R.nlm.nih.gov/63310410R.pdf

6 Radden J, Sadler JZ. The virtuous psychiatrist: character ethics in psychiatric practice. New York: Oxford University Press, 2010.

7 McDougall R. Acting parentally: an argument against sex selection. J Med Ethics 2005;10:601-5.

8 Oakley J. A virtue ethics analysis of disclosure requirements and financial incentives as responses to conflicts of interest in physician prescribing. In: Akabayashi $A$, ed. The future of bioethics: international dialogues. Oxford: Oxford University Press, 2014:669-77.

9 Pham-Kanter G, Alexander GC, Nair K. Effect of physician payment sunshine laws on prescribing. Arch Intern Med 2012;10:819-21.

10 Lowenstein G, Sah S, Cain DM. The unintended consequences of conflicts of interest disclosure. JAMA 2012;7:669-70.

11 Ryle G. The concept of mind. Harmondsworth: Penguin Books, 1963:143-7.

12 Swanton C. Virtue ethics: a pluralistic view. Oxford: Oxford University Press, 2003.

13 Veatch R. The danger of virtue. J Med Philos 1988;4:445.

14 Hare RM. Public policy in a pluralist society. In: Singer $P$, et al. eds. Embryo experimentation. Cambridge: Cambridge University Press, 1990.

15 Oakley J. Virtue ethics and public policy: upholding medical virtue in therapeutic relationships as a case study. J Val Inq 2015; 1 (forthcoming).

16 Tentler A, Silberman J, Paterniti DA, et al. Factors affecting physicians' responses to patients' requests for antidepressants: focus group study. J Gen Intern Med 2008. 23(1):53-7.

17 Aristotle op cit. 